\title{
Oxidative stress is associated with the number of components of metabolic syndrome: LIPGENE study
}

\author{
Elena Maria Yubero-Serrano ${ }^{1}$, Javier Delgado-Lista ${ }^{1}$, Patricia Peña-Orihuela ${ }^{1}$, Pablo Perez-Martinez ${ }^{1}$, \\ Francisco Fuentes ${ }^{1}$, Carmen Marin ${ }^{1}$, Isaac Tunez ${ }^{2}$, Francisco Jose Tinahones ${ }^{3}$, Francisco Perez-Jimenez ${ }^{1}$, \\ Helen M Roche ${ }^{4}$ and Jose Lopez-Miranda ${ }^{1}$
}

Previous evidence supports the important role that oxidative stress (OxS) plays in metabolic syndrome (MetS)-related manifestations. We determined the relationship between the number of MetS components and the degree of OxS in MetS patients. In this comparative cross-sectional study from the LIPGENE cohort, a total of 91 MetS patients (43 men and 48 women; aged between 45 and 68 years) were divided into four groups based on the number of MetS components: subjects with 2, 3, 4 and 5 MetS components $(n=20,31,28$ and 12, respectively). We measured ischemic reactive hyperemia (IRH), plasma levels of soluble vascular cell adhesion molecule-1 (sVCAM-1), total nitrite, lipid peroxidation products (LPO), hydrogen peroxide $\left(\mathrm{H}_{2} \mathrm{O}_{2}\right)$, superoxide dismutase (SOD) and glutathione peroxidase (GPx) plasma activities. sVCAM-1, $\mathrm{H}_{2} \mathrm{O}_{2}$ and LPO levels were lower in subjects with 2 or 3 MetS components than subjects with 4 or 5 MetS components. IRH and total nitrite levels were higher in subjects with 2 or 3 MetS components than subjects with 4 or 5 MetS components. SOD and GPx activities were lower in subjects with 2 MetS components than subjects with 4 or 5 MetS components. Waist circumference, weight, age, homeostatic model assessment- $\beta$, triglycerides (TGs), high-density lipoprotein and sVCAM-1 levels were significantly correlated with SOD activity. MetS subjects with more MetS components may have a higher OxS level.

Furthermore, association between SOD activity and MetS components may indicate that this variable could be the most relevant OxS biomarker in patients suffering from MetS and could be used as a predictive tool to determine the degree of the underlying OxS in MetS.

Experimental \& Molecular Medicine (2013) 45, e28; doi:10.1038/emm.2013.53; published online 21 June 2013

Keywords: cardiovascular risk factors; endothelial dysfunction; LIPGENE study; metabolic syndrome; oxidative stress; redox state

\section{INTRODUCTION}

Metabolic syndrome (MetS) is characterized by different combinations of three or more features such as hyperglycemia, hypertriglyceridemia, low level of high-density lipoprotein (HDL) cholesterol (HDL-C), hypertension and abdominal obesity, ${ }^{1}$ as defined by the criteria of the Third Report of the National Cholesterol Education Program Adult Treatment Panel III. ${ }^{2}$ The incidence of MetS has reached epidemic proportions due to complex interactions between genetic and environmental factors, as well as prevailing sedentary lifestyles and unhealthy dietary habits. Consequently, MetS is considered a major risk factor for diabetes, cardiovascular and kidney diseases in industrialized societies. ${ }^{3}$ Although it is generally accepted that the main pathogenic mechanism underlying the metabolic changes in patients with MetS relies on insulin resistance, there is evidence to indicate that a state of chronic low-level inflammation and oxidative stress (OxS) demonstrates a close link to MetS. ${ }^{4-7}$

$\mathrm{OxS}$ is widely accepted as playing a key mediatory role in the development and progression of multiple pathophysiological conditions, such as endothelial dysfunction, hypertension and atherosclerotic cardiovascular disease. ${ }^{8}$ This process is due to the production of reactive oxygen species and the impairment of antioxidant enzymatic defenses such as

\footnotetext{
${ }^{1}$ Lipids and Atherosclerosis Unit, IMIBIC/Reina Sofia University Hospital/University of Cordoba, and CIBER Fisiopatologia Obesidad y Nutricion (CIBEROBN), Instituto de Salud Carlos III, Spain; ${ }^{2}$ Department of Biochemistry and Molecular Biology (IMIBIC), Faculty of Medicine, University of Cordoba, Cordoba, Spain; ${ }^{3}$ Biomedical Research Laboratory, Endocrinology Department, Hospital Virgen de la Victoria, Malaga, Spain, and CIBER Fisiopatologia Obesidad y Nutricion (CIBEROBN), Instituto de Salud Carlos III, Spain and ${ }^{4}$ Nutrigenomics Research Group, School of Public Health and Population Science, UCD Conway Institute, University College Dublin, Dublin, Ireland

Correspondence: Professor J Lopez-Miranda, Lipids and Atherosclerosis Unit, IMIBIC/Reina Sofia University Hospital/University of Cordoba, Avda. Menendez Pidal s/n, 14004 Córdoba, Spain.

E-mail: jlopezmir@uco.es
}

Received 1 January 2013; revised 3 March 2013; accepted 2 April 2013 
superoxide dismutase (SOD) or glutathione peroxidase (GPx), as well as the deposition of advanced glycation end products and oxidized low-density lipoproteins in the vascular wall. ${ }^{6,9,10}$ Moreover, OxS is also present in insulin resistance and concomitant inflammation. Interestingly, in association with obesity (with several MetS components), patients with insulin resistance and hyperglycemia have been shown to have a propensity toward aggressive cardiovascular disease, proinflammatory changes and a reduced nitric oxide $(\mathrm{NO})$ bioavailability. ${ }^{11}$ Similarly, MetS patients exhibit activation of biochemical pathways leading to an increased delivery of reactive oxygen species, altered antioxidant protection and increased lipid peroxidation (LPO). ${ }^{12}$ Nevertheless, there is still a lack of data in this field. It is unclear whether the accumulation of factors related with MetS increases the degree of underlying OxS.

Following these assumptions, the purpose of this study was to investigate whether the degree of $\mathrm{OxS}$ is influenced by the number of components of MetS. We analyzed the activity of the main antioxidant enzymes ( $\mathrm{SOD}$ and $\mathrm{GPx}$ ) as well as $\mathrm{OxS}$ biomarkers (LPO, hydrogen peroxide $\left(\mathrm{H}_{2} \mathrm{O}_{2}\right)$ and $\mathrm{NO}$ ) in a cross-sectional study of MetS patients of four groups divided according to the number of MetS components: subjects with 2, 3, 4 and 5 MetS components.

\section{MATERIALS AND METHODS}

\section{Subjects and design}

This study was conducted within the framework of the LIPGENE study ('Diet, genomics and the metabolic syndrome: an integrated nutrition, agro-food, social and economic analysis'), a Framework VI Integrated Project funded by the European Union. ${ }^{13}$

Subject eligibility was determined using a modified version of the National Cholesterol Education Program criteria for MetS, according to the published criteria. ${ }^{14}$

Subjects were required to meet at least two of the following five criteria: waist circumference $>102 \mathrm{~cm}$ (men) or $>88 \mathrm{~cm}$ (women); fasting glucose $5.5-7.0 \mathrm{mmoll}^{-1}$; TGs $\geqslant 1.5 \mathrm{mmoll}^{-1}$; HDL-C $<1.0 \mathrm{mmoll}^{-1}$ (men) or $<1.3 \mathrm{mmoll}^{-1}$ (women); blood pressure (BP) $\geqslant 130 / 85 \mathrm{~mm} \mathrm{Hg}$ or treatment of previously diagnosed hypertension. We used a subgroup of pre-intervention data for 91 subjects (43 men and 48 women), which conformed to the LIPGENE inclusion and exclusion criteria (Supplementary Table 1). ${ }^{15}$

All participants provided written informed consent and underwent a comprehensive medical history, physical examination and clinical chemistry analysis before enrollment. Participants displayed no signs of cardiac dysfunction or hepatic, renal and thyroid diseases and were requested to maintain their regular physical activity and lifestyle. Participants were also asked to record in a diary any event that could affect the outcome of the study, such as stress, change in smoking habits and alcohol consumption or intake of foods not included in the experimental design. None of the participants showed evidence of high alcohol consumption or a family history of early-onset cardiovascular disease, nor were any active smokers. All patients were free from cardiovascular complications at the time of the enrollment. The study was carried out in the Lipid and Atherosclerosis Unit at the Reina Sofia University Hospital, from February 2005 to April 2006. The experimental protocol was approved by the local ethics committee according to the Helsinki Declaration. The study was registered with the US National Library of Medicine Clinical Trials registry (NCT00429195).

\section{Anthropometric measurements}

After recording clinical histories and conducting physical examinations, we obtained the following anthropometric measurements for each individual: weight, height, body mass index and waist circumference. Weight was measured while the subject was wearing light indoor clothing, without shoes and after voiding. Height was obtained with a stadiometer graduated in millimeters. The subject was barefoot with the back and head in contact with the stadiometer in the Frankfurt horizontal plane. Body mass index was calculated by dividing weight $(\mathrm{kg})$ by height squared $\left(\mathrm{m}^{2}\right)$. Waist circumference $(\mathrm{cm})$ was measured to the nearest $0.5 \mathrm{~cm}$ with a tape measure at the umbilical scar level. A non-stretchable tape measure was used to measure waist circumference. The measurement was taken directly on the skin with the subject in a standing position with the abdomen relaxed, the arms at the sides and the feet together. We used the homeostatic model assessment index for insulin resistance $\left(\mathrm{HOMA}_{\mathrm{IR}}\right.$ : fasting insulin $\left(\mathrm{mUl}^{-1}\right) \times$ fasting glucose $\left.\left(\mathrm{mmoll}^{-1}\right) / 22.5\right)$ and HOMA $\beta$-cell function as the index of insulin secretory function derived from fasting plasma glucose and insulin concentrations, calculated as $20 \times$ fasting insulin $\left(\mathrm{mUl}^{-1}\right) /$ fasting glucose $\left(\mathrm{mmoll}^{-1}\right)-3.5^{16}$ Insulin sensitivity was estimated by a quantitative insulin sensitivity check index (QUICKI) $(1 /[\log$ insulin $\left(\mathrm{mUl}^{-1}\right)+\log$ baseline glucose $\left.\left.\left(\mathrm{mg} \mathrm{dl}^{-1}\right)\right]\right) .{ }^{17} \mathrm{BP}$ was measured using an automatic BP device. In accordance with the European Society of Hypertension Guidelines, ${ }^{18}$ BP measurement was obtained with an appropriately sized cuff positioned at the heart level and after the patient had been relaxed for at least $5 \mathrm{~min}$. The same arm was used for each measurement, and the average of two measurements was used for data processing.

\section{Biochemical determinations}

Plasma samples. Blood was collected in tubes containing ethylene diaminetetraacetic acid to yield a final concentration of $0.1 \%$ ethylene diaminetetraacetic acid. Plasma was separated from red cells by centrifugation at $1500 \mathrm{~g}$ for $15 \mathrm{~min}$ at $4^{\circ} \mathrm{C}$ within $1 \mathrm{~h}$ of extraction. Plasma was immediately aliquoted and stored at $-80^{\circ} \mathrm{C}$ until analysis.

Biochemical analysis. The lipid variables were analyzed with a modular autoanalyzer (DDPPII Hitachi; Roche, Basel, Switzerland) with the use of Boehringer-Mannheim reagents. TGs in plasma were assayed by means of enzymatic procedures. ${ }^{19} \mathrm{HDL}-\mathrm{C}$ was measured by analyzing the supernatant obtained following precipitation of a plasma aliquot in dextran sulfate- $\mathrm{Mg}^{2+}$, as described by Warnick et al. ${ }^{20}$ Plasma glucose concentrations were measured with an Architect-CG16000 analyzer (Abbott Diagnostics, Tokyo, Japan) by the hexokinase method. Plasma insulin concentrations were measured by chemoluminescence with an Architect-I2000 analyzer (Abbott Diagnostics, Tokyo, Japan). High-sensitivity C-reactive protein concentrations were measured according to Rifai et al. ${ }^{21}$ The estimated glomerular filtration rate was calculated using the Chronic Kidney Disease Epidemiology Collaboration equation. ${ }^{22}$

\section{Study of endothelial function using laser Doppler}

The Laser-Doppler linear Periflux 5000 (Perimed S.A., Stockholm, Sweden) was used to measure ischemic reactive hyperemia (IRH). 
We found an inter-study variability of $8.85 \%$ and an intra-study variability of $8.7 \%$.

Briefly, capillary flow of the second finger of the dominant arm of the patient was assessed for $1 \mathrm{~min}$ before $(\mathrm{t} 0)$ and after applying $4 \mathrm{~min}(\mathrm{td})$ of ischemia to the arm using a sphygmomanometer. The $\mathrm{IRH}$ was obtained via $\mathrm{IRH}=\left(\mathrm{AUC}_{\mathrm{td}}-\mathrm{AUC}_{\mathrm{t} 0}\right) \times 100 \mathrm{AUC}_{\mathrm{t} 0}$.

\section{sVCAM-1 levels}

Plasma concentrations of soluble vascular cell adhesion molecule-1 (sVCAM-1) were determined in duplicate with commercially available ELISA kits (R\&D Systems, Minneapolis, MN, USA). Each assay was calibrated with sVCAM-1 standard curves. Absorbance was evaluated in an EIA plate reader (DTX 880 Multimode Detector; Beckman Coulter, Brea, CA, USA) at a wavelength of $450 \mathrm{~nm}$. The minimum detectable level of sVCAM-1 was $0.17 \mathrm{ng} \mathrm{ml}^{-1}$.

\section{Determination of OxS biomarkers}

LPO is a mechanism of cellular and molecular injury. Plasmatic levels of LPO were determined using the Bioxytech LPO-586 Kit (OXIS International, Portland, OR, USA), ${ }^{23}$ an intra-assay coefficient of variation of $5.8 \%$ and an inter-assay coefficient of variation of $7.2 \%$. The kit uses a chromatogenic reagent that reacts with malondialdehyde +4 -hydroxyalkenals. The absorbance was evaluated in a spectrophotometer (UV-1603; Shimadzu, Kyoto, Japan) at a wavelength of $586 \mathrm{~nm}$.

Plasmatic levels of $\mathrm{H}_{2} \mathrm{O}_{2}$ were determined using the Bioxytech $\mathrm{H} 2 \mathrm{O} 2-560$ Assay (OXIS International), an intra-assay coefficient of variation of $5.2 \%$ and an inter-assay coefficient of variation of $8.1 \%$. The reaction was monitored at $560 \mathrm{~nm}$.

Nitric oxide (NO) is a free gas produced endogenously by a variety of mammalian cells. This molecule induces vasodilatation and inhibits platelet aggregation and adhesion to the vascular endothelium. Total nitrite (nitrite and nitrate) was used as an indicator of NO production and was assayed using the Griess method, ${ }^{24}$ with an intra-assay coefficient of variation of $6.1 \%$, and an inter-assay coefficient of variation of $7.7 \%$. The reaction was monitored at $540 \mathrm{~nm}$.

\section{Antioxidant enzyme activities}

Total SOD (E.C: 1.15.1.1) activity was determined by colorimetric assay in plasma at wavelength of $525 \mathrm{~nm}$, according to the method described by McCord and Fridovich et al., ${ }^{25}$ with an intra-assay coefficient of variation of $7.3 \%$, and an inter-assay coefficient of variation of $8.7 \%$. GPx (E.C.: 1.11.1.9) activity was evaluated in plasma by the Flohe and Gunzler method, ${ }^{26,27}$ with an intra-assay coefficient of variation of $6.5 \%$ and an inter-assay coefficient of variation of $7.2 \%$. The GPx assay is based on the oxidation of nicotinamide adenine dinucleotide phosphate to $\mathrm{NAD}+$, catalyzed by a limiting concentration of glutathione reductase, with maximum absorbance at $340 \mathrm{~nm}$. The absorbance was evaluated in a Shimadzu UV-1603 spectrophotometer.

\section{Statistical analysis}

The Statistical Package for the Social Sciences (SPSS 18.0 for Windows, Chicago, IL, USA) was used for statistical comparisons. The Kolmogorov-Smirnov test did not reveal a significant departure from the norms in the distribution of variance values. To evaluate data variation, Student's $t$-test and a univariate analysis of variance were performed with gender and waist circumference (Supplementary Table 2) included as covariates. Bonferroni's test was used when post hoc analysis was required (Supplementary Table 3). Pearson's linear correlation coefficient was calculated, and a multiple linear regression analysis was performed. Differences were considered to be significant when $P<0.05$. All data presented in text and tables are expressed as the means \pm s.e.

\section{RESULTS}

\section{Biochemical and anthropometric characteristics and} metabolic assessment

The anthropometric, biochemical, BP and metabolic parameters of the subjects with a different number of MetS components are shown in Table 1. Plasma TG, glucose and insulin levels and baseline $\operatorname{HOMA}_{\mathrm{IR}}(P=0.009)$ were higher in the subjects with 4 and $5 \mathrm{MetS}$ components compared with the subjects with 2 and 3 MetS components (all $P<0.05$; Table 1). Baseline HOMA $\beta$ and QUICKI were lower in the subjects with 4 or 5 MetS components compared with the subjects with 2 or 3 MetS components (all $P<0.05$; Table 1). High-sensitivity C-reactive protein levels were higher and estimated glomerular filtration rate was lower in the subjects with $5 \mathrm{MetS}$ components than other subjects (all $P<0.05$ ). In addition, we found that body mass index, waist circumference and diastolic blood pressure were lower and HDL-C was higher in the subjects with 2 MetS components compared with the other subjects (all $P<0.05$; Table 1). We did not find significant differences with respect to age (mean age: 58 years old; range: $45-68$ years old) or systolic blood pressure (SBP) between the four groups of subject with MetS (Table 1).

\section{Study of endothelial function}

IRH decreased in the following order: 2 and 3 MetS components $>4$ components $>5$ components (all $P<0.05$ ) (Figure 1a). In addition, we observed lower plasma sVCAM-1 levels in the subjects with 2-3 MetS components than the subjects with 4-5 MetS components (all $P<0.05$; Figure 1b). Total plasma nitrite levels were higher in the subjects with 2-3 MetS components than the subjects with 5 MetS components (all $P<0.05$; Figure 1c).

\section{Biomarkers of OxS}

Plasma $\mathrm{H}_{2} \mathrm{O}_{2}$ and LPO levels were higher in the subjects with 5 MetS components compared with the subjects with 2 and 3 MetS components (all $P<0.05$; Figures $2 \mathrm{a}$ and $\mathrm{b}$ ).

\section{Antioxidant enzyme activities}

Plasma SOD activity was lower in the subjects with 2 MetS components compared with the subjects with 3, 4 and 5 MetS components (all $P<0.05$; Figure 3a).

We found less plasma GPx activity in the subjects with 2 and 3 MetS components than the subjects with 4 and 5 MetS components (all $P<0.05$; Figure $3 \mathrm{~b}$ ).

\section{Correlation and regression analysis}

We observed significant correlations of plasma SOD activity with weight $(r=0.299, \quad P=0.004)$, waist circumference $(r=0.323, P=0.002)$, TG level $(r=0.238, P=0.023)$, HDL level $(r=-0.357, P=0.001)$, age $(r=-0.214, P=0.042)$, 
Table 1 Blood pressure, biochemical and anthropometric characteristics and metabolic assessment of the study groups ${ }^{a, b}$

\begin{tabular}{|c|c|c|c|c|c|}
\hline & $\begin{array}{c}\text { Subjects with } \\
2 \text { MetS components } \\
\text { ( } \mathrm{n}=20 ; 13 \text { men } \\
7 \text { women) }\end{array}$ & $\begin{array}{c}\text { Subjects with } \\
3 \text { MetS components } \\
\text { ( } \mathrm{n}=31 ; 12 \text { men, } \\
19 \text { women) }\end{array}$ & $\begin{array}{c}\text { Subjects with } \\
4 \text { MetS components } \\
\text { ( } \mathrm{n}=28 ; 12 \text { men, } \\
16 \text { women) }\end{array}$ & $\begin{array}{c}\text { Subjects with } \\
5 \text { MetS components } \\
(\mathrm{n}=12 ; 6 \text { men, } \\
6 \text { women })\end{array}$ & P-values \\
\hline Age (years) & $64.61 \pm 1.46$ & $57.06 \pm 1.47$ & $56.23 \pm 1.37$ & $58.84 \pm 0.51$ & 0.243 \\
\hline $\mathrm{TG}\left(\mathrm{nmol} \mathrm{I}^{-1}\right)$ & $1.10 \pm 0.04^{\mathrm{a}}$ & $1.24 \pm 0.09^{a}$ & $1.96 \pm 0.16^{b}$ & $2.11 \pm 0.05^{b}$ & $<0.001$ \\
\hline Glucose $\left(\mathrm{nmol} \mathrm{I}^{-1}\right)$ & $5.42 \pm 0.07^{a}$ & $6.04 \pm 0.26^{b}$ & $6.35 \pm 0.12^{b}$ & $6.89 \pm 0.09^{b}$ & $<0.001$ \\
\hline HDL-C (nmoll-1) & $1.33 \pm 0.04^{a}$ & $1.15 \pm 0.04^{\mathrm{b}}$ & $1.06 \pm 0.04^{b}$ & $0.97 \pm 0.02^{b}$ & $<0.001$ \\
\hline BMI & $30.93 \pm 0.65^{a}$ & $34.21 \pm 0.71^{b}$ & $36.13 \pm 0.61^{b}$ & $35.07 \pm 0.41^{b}$ & 0.011 \\
\hline Insulin $\left(\mathrm{mU} \mathrm{I}^{-1}\right)$ & $10.13 \pm 0.71^{a}$ & $10.91 \pm 0.93^{a}$ & $14.85 \pm 0.82^{b}$ & $15.23 \pm 0.66^{b}$ & 0.001 \\
\hline Waist circumference $(\mathrm{cm})$ & $102.32 \pm 2.05^{a}$ & $106.36 \pm 1.63^{b}$ & $108.78 \pm 1.60^{\mathrm{b}}$ & $109.34 \pm 0.92 c$ & 0.018 \\
\hline $\operatorname{hsCRP}\left(\left.m g\right|^{-1}\right)$ & $2.06 \pm 0.52^{a}$ & $4.57 \pm 1.21^{b}$ & $6.04 \pm 1.02^{b}$ & $8.43 \pm 1.57 c$ & $<0.001$ \\
\hline eGFR $\left(\mathrm{ml} \mathrm{min}-1\right.$ per $\left.1.73 \mathrm{~m}^{2}\right)$ & $92.08 \pm 3.61^{a}$ & $86.55 \pm 2.84^{a}$ & $84.87 \pm 2.82^{\mathrm{a}}$ & $72.78 \pm 2.59^{b}$ & 0.012 \\
\hline $\mathrm{SBP}(\mathrm{mm} \mathrm{Hg})$ & $137 \pm 2.25$ & $142 \pm 2.93$ & $145 \pm 2.75$ & $144 \pm 1.44$ & 0.123 \\
\hline $\mathrm{DBP}(\mathrm{mm} \mathrm{Hg})$ & $80 \pm 1.81^{a}$ & $85 \pm 1.35^{b}$ & $89 \pm 1.56^{b}$ & $91 \pm 1.26 c$ & $<0.001$ \\
\hline $\mathrm{HOMA}_{I R}$ & $2.41 \pm 0.33^{a}$ & $2.55 \pm 0.13^{a}$ & $4.29 \pm 0.35^{b}$ & $4.66 \pm 0.32^{b}$ & 0.002 \\
\hline НОМА $\beta$ & $118.13 \pm 1.95^{\mathrm{a}}$ & $119.17 \pm 2.53^{a}$ & $112.70 \pm 5.87^{b}$ & $110.11 \pm 3.11^{\mathrm{b}}$ & 0.032 \\
\hline QUICKI & $0.340 \pm 0.006^{a}$ & $0.341 \pm 0.008^{a}$ & $0.313 \pm 0.005^{b}$ & $0.309 \pm 0.005^{b}$ & 0.023 \\
\hline
\end{tabular}

Abbreviations: BMI, body mass index; DBP, diastolic blood pressure; eGFR, estimated glomerular filtration rate; HDL-C, high-density lipoprotein-cholesterol; HOMA homeostatic model assessment index for insulin resistance; HOMA $\beta$, homeostatic model assessment index of insulin secretory function; hsCRP, high-sensitivity C-reactive protein; MetS, metabolic syndrome; QUICKI, quantitative insulin sensitivity check index; SBP, systolic blood pressure; TG, triglycerides.

avalues are means \pm s.e. (all such values).

bMeans in a column with different letters are significantly different, $P<0.05$.

VCAM-1 level $(r=0.292, \quad P=0.005)$ and HOMA $\beta$ $(r=-0.244, P=0.028)$ (Table 2).

A multiple linear regression was performed. Waist circumference, gender, age, BP, IRH, NO, TG, glucose, sVCAM-1, LPO and HDL levels were included (Table 3). Only sVCAM-1 $(\beta=0.410 ; \quad P=0.017)$, waist circumference $(\beta=0.391$; $P=0.029), \quad$ TG $\quad(\beta=0.344 ; \quad P=0.038) \quad$ and $\quad$ HOMA $\beta$ ( $\beta=0.406 ; P=0.036)$ were significant independent predictors of SOD activity (Table 3 ).

\section{DISCUSSION}

MetS comprises a cluster of cardiovascular risk factors (low HDL-C, elevated BP, fasting glucose and TG, and abdominal obesity) ${ }^{1}$ leading to accelerated atherosclerosis and an increased risk of type 2 diabetes. Additionally, MetS is associated with major cardiovascular events and a high mortality rate. ${ }^{28,29}$ Although it is generally accepted that the main pathogenic mechanism underlying the development of metabolic changes in patients with MetS relies on insulin resistance, a large body of evidence supports the concept that increased $\mathrm{OxS}$ and a state of chronic low-level inflammation may have important roles in MetS-related manifestations, including atherosclerosis, inflammation, endothelial dysfunction, hypertension and type 2 diabetes mellitus. ${ }^{4,30,31}$ These data indicate that OxS could be an early event in the pathology of these chronic diseases rather than merely a consequence. However, the relationship between the number of MetS components and OxS in subjects with MetS has seldom been studied. ${ }^{32}$ With regard to the influence of the number of MetS components on OxS, our results showed that the higher the number of components, the greater the degree of OxS, which leads to increased plasma SOD and GPx activities, plasma $\mathrm{H}_{2} \mathrm{O}_{2}$, LPO and sVCAM-1 levels, and decreased IRH and total plasma nitrite levels. Fujita et al. ${ }^{33}$ demonstrated that systemic OxS increases in subjects with MetS and that this stress is closely linked to the accumulation of visceral fat and an increase in other anthropometric variables. Thus, we observed a higher body mass index, waist circumference, diastolic blood pressure, $\mathrm{HOMA}_{\mathrm{IR}}$ and TG, glucose and insulin levels, and lower HDL-C levels and HOMA $\beta$ and QUICKI indexes when OxS increases.

It has also been suggested that increased OxS originates from mitochondrial dysfunction in patients with MetS. ${ }^{34,35}$ In response to OxS and to prevent oxidative damage, cells attempt to strengthen their antioxidant arsenal as the first line of defense. SOD, GPx and catalase (CAT) are considered primary antioxidant enzymes because they are involved in the direct elimination of reactive oxygen species. One major contributor to oxidative damage is $\mathrm{H}_{2} \mathrm{O}_{2}$, which is converted from the superoxide that originated from the mitochondria. CAT and SOD ameliorate the damaging effects of $\mathrm{H}_{2} \mathrm{O}_{2}$ and superoxides by converting these compounds into the less damaging, benign molecules, oxygen and water. GPx decomposes $\mathrm{H}_{2} \mathrm{O}_{2}$ and/or $\mathrm{ROOH}$, thereby neutralizing their toxicity. Any changes in one of these systems may upset the equilibrium and result in cellular damage. ${ }^{36}$ Previous studies have shown that the expression of SOD is upregulated by reactive oxygen species ${ }^{37}$ indicating that the increase in $\mathrm{H}_{2} \mathrm{O}_{2}$ levels in the subjects with 4 or $5 \mathrm{MetS}$ components could explain the greater increase in SOD and GPx activities in these groups of subjects. Moreover, we also found an increase in LPO levels in the subjects with 4 or 5 MetS components with 

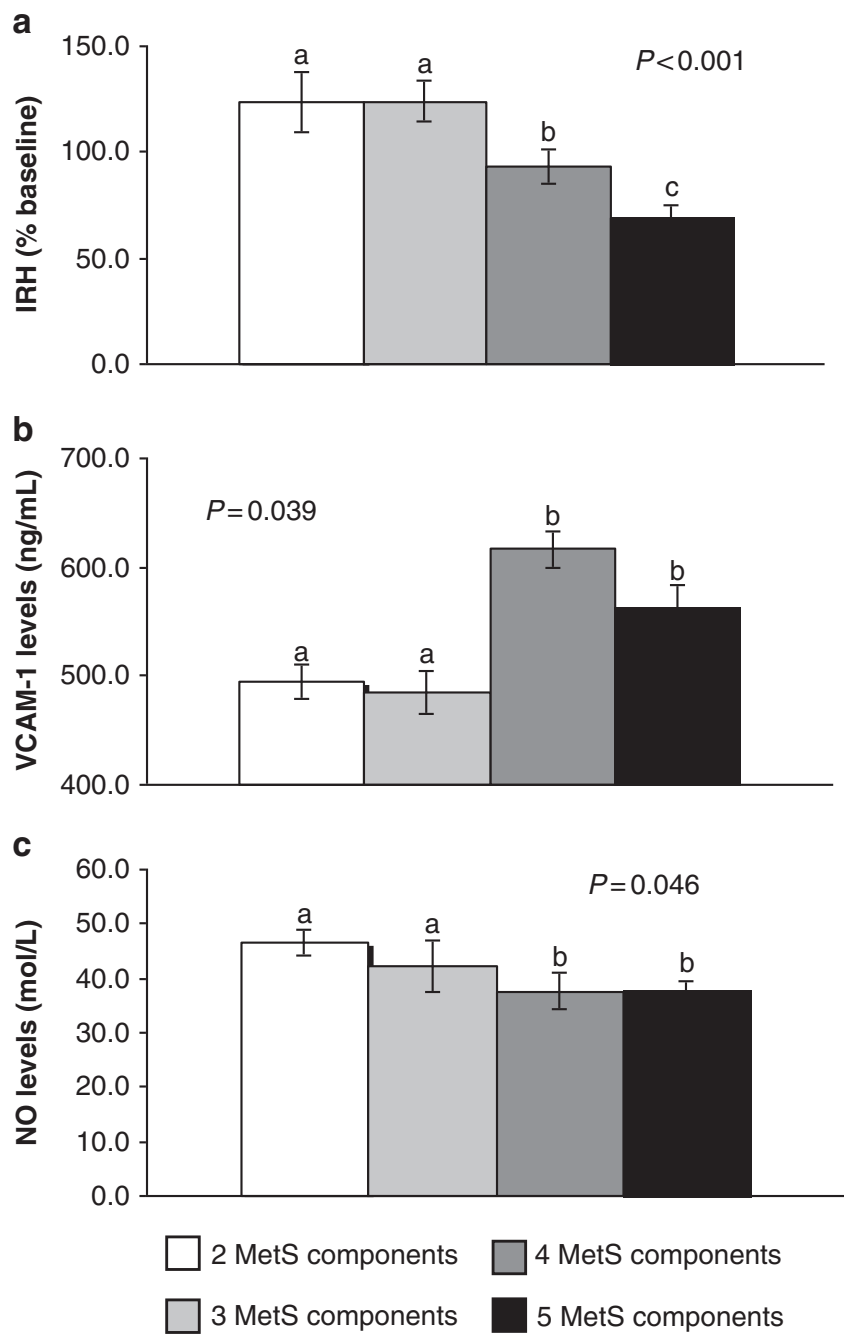

Figure 1 Ischemic reactive hyperemia (IRH) (a), soluble vascular cell adhesion molecule-1 (sVCAM-1) levels (b) and total nitrite levels (c) in plasma according to the number of metabolic syndrome (MetS) components. The data were analyzed using analysis of variance for repeated measurements. All values represent the means \pm s.e. Bars with different superscript letters depict significant differences $(P<0.05)$. NO, nitric oxide.

respect to the other groups. LPO is an index of lipid damage, especially damage associated with OxS derived from free radicals. Increases in LPO levels have been observed in several human diseases including diabetes, arthritis and other inflammatory diseases, as well as in patients with MetS. ${ }^{35,38}$

OxS, through superoxide anion production, decreases NO availability. ${ }^{39}$ It has also been described that impaired endothelial function is a key step in the pathogenesis of cardiovascular disease and that elevated levels of sVCAM-1 predict the incidental development of cardiovascular disease events. ${ }^{40}$ Thus, the improved bioavailability of NO (total nitrite) in subjects with 2 or 3 MetS components, as was also shown in our study, may be an indirect effect of a lower production of superoxide anions. Additionally, this observation coincides with higher IRH and lower plasma sVCAM-1 levels measured in these subjects.
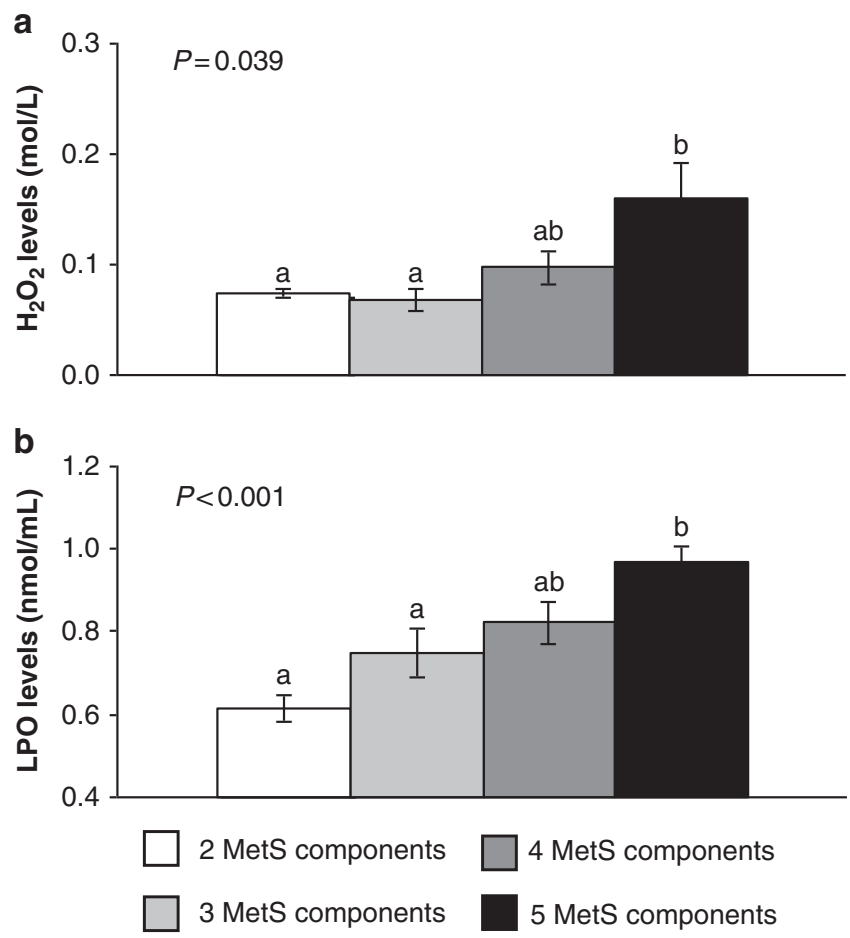

Figure 2 Hydrogen peroxide $\left(\mathrm{H}_{2} \mathrm{O}_{2}\right)$ levels (a) and lipid peroxidation product (LPO) levels (b) in plasma according to the number of metabolic syndrome (MetS) components. The data were analyzed using analysis of variance for repeated measurements. All values represent the means \pm s.e. Bars with different superscript letters depict significant differences $(P<0.05)$.

Table 2 Correlation between plasma SOD activity and other factors $^{\mathrm{a}}$

\begin{tabular}{lc}
\hline & SOD activity \\
\hline Age & $-0.214^{*}$ \\
Weight & $0.299^{* *}$ \\
Waist circumference $(\mathrm{cm})$ & $0.323^{* *}$ \\
TG & $0.238^{*}$ \\
HDL & $-0.357^{* *}$ \\
VCAM-1 & $0.292^{*}$ \\
HOMA $\beta$ & $-0.244^{*}$
\end{tabular}

Abbreviations: HDL, high-density lipoprotein-cholesterol; HOMA $\beta$, homeostatic model assessment index of insulin secretory function; SOD, superoxide dismutase; TG, triglycerides; VCAM-1, vascular cell adhesion molecule-1. aPearson's correlation: ${ }^{*} P<0.05 ;{ }^{*} P<0.001$.

Similarly, we also found correlations between weight, waist circumference, TG, HDL and sVCAM- 1 levels, HOMA $\beta$ index and SOD activity. These results could partially account for the increase in the production of superoxide anions, as seen in conditions that involve hypertriglyceridemia and obesity. ${ }^{41}$

We also found that the SOD activity is the most relevant OxS marker because several individual MetS components were correlated with this variable. Although the SOD activity may be directly or indirectly regulated by the redox balance, certain SOD activity is affected only by factors intrinsic to the individual, such as genetic factors. 

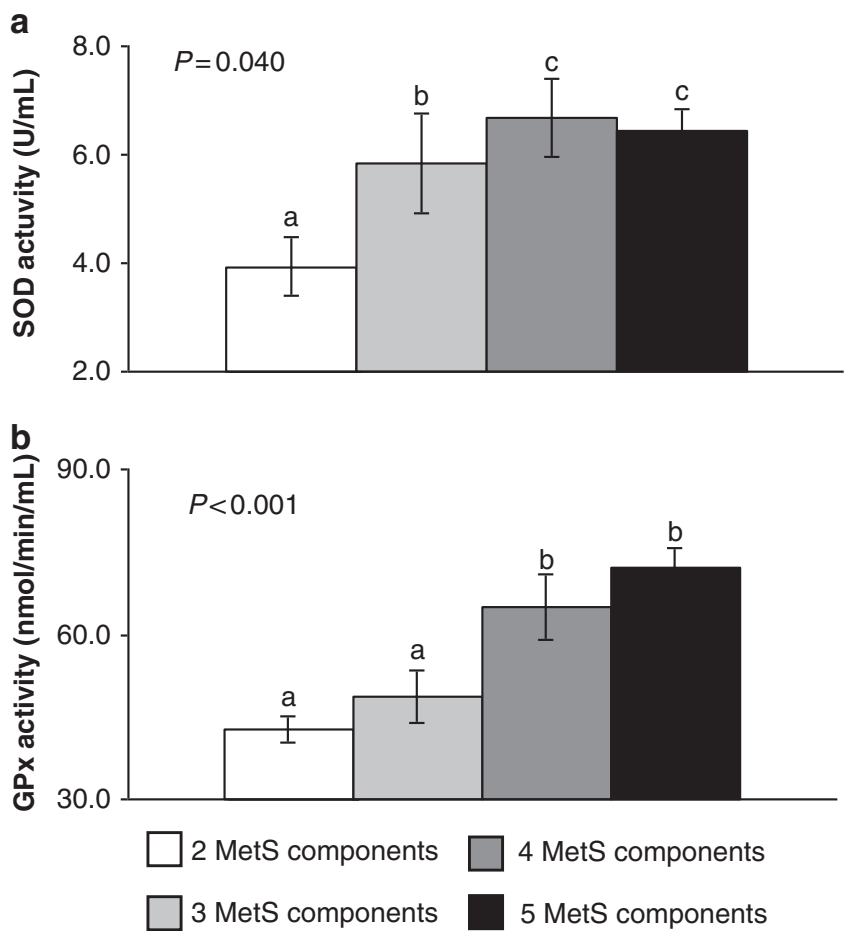

Figure 3 Superoxide dismutase (SOD) activity (a) and glutathione peroxidase (GPX) activity (b) in plasma according to the number of metabolic syndrome (MetS) components. The data were analyzed using analysis of variance for repeated measurements. All values represent the means \pm s.e. Bars with different superscript letters depict significant differences $(P<0.05)$.

Table 3 Correlations of plasma SOD activity with different factors by multiple regression analysis ${ }^{\mathrm{a}}$

\begin{tabular}{lcccc}
\hline & $\begin{array}{c}\text { Regression } \\
\text { coefficient }\end{array}$ & s.e. & $\beta$-value & P-value \\
\hline Waist circumference $(\mathrm{cm})$ & 0.123 & 0.041 & 0.288 & 0.005 \\
TG $\left.(\mathrm{nmolI})^{-1}\right)$ & 1.080 & 0.559 & 0.288 & 0.004 \\
VCAM-1 $\left.(\mathrm{ng} \mathrm{ml})^{-1}\right)$ & 0.006 & 0.002 & 0.251 & 0.011
\end{tabular}

Abbreviations: SOD, superoxide dismutase; TG, triglycerides; VCAM-1, vascular cell adhesion molecule- 1 .

a A multiple regression analysis was used to examine the correlations of plasma SOD activity with different factors of the study, SOD activity as dependent variable and waist circumference, TG and VCAM-1 levels as independent variables.

Our study has some limitations. First, this cross-sectional study does not determine causality between the number of components of MetS with OxS. Second, this study examines the redox state by measuring plasma concentrations but does not evaluate the effects on various tissues involved. However, the findings obtained via plasma concentrations could reflect what is occurring in different body tissues. Another limitation of our study is that we did not include any subjects with 0 or 1 MetS criteria. This limitation is due to the characteristics of the LIPGENE study; additional studies including such criteria should thus be performed. Finally, the complexity of our study necessitated the use of a small sample population; it would be difficult to broaden the scope of the study to larger populations. However, it would be optimal if this study could be reproduced in large populations. Larger, prospective studies are needed to establish the relationship between the number of components of MetS and the degree of OxS.

In conclusion, MetS subjects with more MetS components may have a higher level of OxS. Furthermore, association between SOD activity and several MetS components may indicate that SOD activity could be the most relevant OxS biomarker in patients suffering from MetS. Measurement of SOD activity could be used as a predictive tool to determine the degree of underlying $\mathrm{OxS}$ in this disease.

These findings suggest that studying the redox state in early MetS patients may provide a starting point for understanding the pathways that contribute to both the development of MetS and its subsequent complications.

\section{CONFLICT OF INTEREST}

The authors declare no conflict of interest.

\section{ACKNOWLEDGEMENTS}

This research was supported partly by grants from the Ministerio de Ciencia e Innovación (AGL2006-01979, AGL2009-12270 to JL-M), ('CB06/03/0047-CIBER Fisiopatologia de la Obesidad y Nutrition' is an ISCIII grant awarded to FP-J), Consejería de Innovación, Ciencia y Empresa, Junta de Andalucía (P06-CTS-01425 and CVI-7450 to JL-M); Consejería de Salud, Junta de Andalucía (06/128, 07/43, PI0193/2009 to JL-M, 06/129 to FP-J).

Author contributors: The authors' responsibilities were as followsJL-M designed research and conducted research; JD-L, PP-M and JL$M$ provided materials or participants; JD-L, PP-O, FF, CM and EMY-S collected the data; EMY-S, JD-L, PP-O and IT analyzed data; EMY-S wrote the paper; PP-M, JD-L, HMR and FJT provided significant advice and support in reviewing and drafting the paper; JL-M and FP-J held the main responsibility for the final content. All the authors read and approved the final manuscript.

1 Reaven G. Metabolic syndrome: pathophysiology and implications for management of cardiovascular disease. Circulation 2002; 106: 286-288.

2 National Cholesterol Education Program (NCEP) Expert Panel on Detection E, and Treatment of High Blood Cholesterol in Adults (Adult Treatment Panel III). Third Report of the National Cholesterol Education Program (NCEP) Expert Panel on Detection, Evaluation, and Treatment of High Blood Cholesterol in Adults (Adult Treatment Panel III) final report. Circulation 2002; 106: 3143-3421.

3 Mokdad AH, Ford ES, Bowman BA, Dietz WH, Vinicor F, Bales VS et al. Prevalence of obesity, diabetes, and obesity-related health risk factors, 2001. JAMA 2003; 289: 76-79.

4 Ceriello A, Motz E. Is oxidative stress the pathogenic mechanism underlying insulin resistance, diabetes, and cardiovascular disease? The common soil hypothesis revisited. Arterioscler Thromb Vasc Biol 2004; 24: 816-823.

5 Furukawa S, Fujita $T$, Shimabukuro $M$, Iwaki $M$, Yamada $Y$, Nakajima $Y$ et al. Increased oxidative stress in obesity and its impact on metabolic syndrome. J Clin Invest 2004; 114: 1752-1761.

6 Kim M, Paik JK, Kang R, Kim SY, Lee SH, Lee JH. Increased oxidative stress in normal-weight postmenopausal women with metabolic syndrome compared with metabolically healthy overweight/obese individuals. Metabolism: Clin Experimental 2012; pii S0026-0495: 00388-5. 
7 Chen SJYC, Huang YC, Lee BJ, Hsia S, Lin PT. Relationships between inflammation, adiponectin, and oxidative stress in metabolic syndrome. PLoS One 2012; 7: e45693.

8 Aizawa K, Shoemaker JK, Overend TJ, Petrella RJ. Metabolic syndrome, endothelial function and lifestyle modification. Diab Vasc Dis Res 2009; 6: 181-189.

9 Chaves FJ, Mansego ML, Blesa S, Gonzalez-Albert V, Jimenez J, Tormos $\mathrm{MC}$ et al. Inadequate cytoplasmic antioxidant enzymes response contributes to the oxidative stress in human hypertension. Am J Hypertens 2007; 20: 62-69

10 Abdilla N, Tormo MC, Fabia MJ, Chaves FJ, Saez G, Redon J. Impact of the components of metabolic syndrome on oxidative stress and enzymatic antioxidant activity in essential hypertension. J Hum Hypertens 2007; 21: 68-75.

11 van Etten RW, de Koning EJ, Verhaar MC, Gaillard CA, Rabelink TJ, Impaired NO-dependent vasodilation in patients with Type II (non-insulindependent) diabetes mellitus is restored by acute administration of folate. Diabetologia 2002; 45: 1004-1010.

12 Grattagliano I, Palmieri VO, Portincasa P, Moschetta A, Palasciano G. Oxidative stress-induced risk factors associated with the metabolic syndrome: a unifying hypothesis. J Nutr Biochem 2008; 19: 491-504.

13 Tierney AC, McMonagle J, Shaw DI, Gulseth HL, Helal O, Saris WH et al. Effects of dietary fat modification on insulin sensitivity and on other risk factors of the metabolic syndrome-LIPGENE: a European randomized dietary intervention study. Int J Obes 2011; 35: 800-809.

14 Expert Panel on Detection, Evaluation, and Treatment of High Blood Cholesterol in Adults. Executive Summary of The Third Report of The National Cholesterol Education Program (NCEP) Expert Panel on Detection, Evaluation, And Treatment of High Blood Cholesterol In Adults (Adult Treatment Panel III). JAMA 2001; 285: 2486-2497.

15 Perez-Martinez P, Moreno-Conde M, Cruz-Teno C, Ruano J, Fuentes F, Delgado-Lista $\mathrm{J}$ et al. Dietary fat differentially influences regulatory endothelial function during the postprandial state in patients with metabolic syndrome: from the LIPGENE study. Atherosclerosis 2010; 209: 533-538.

16 Matthews DR, Hosker JP, Rudenski AS, Naylor BA, Treacher DF, Turner RC. Homeostasis model assessment: insulin resistance and beta-cell function from fasting plasma glucose and insulin concentrations in man. Diabetologia 1985; 28: 412-419.

17 Conwell LS, Trost SG, Brown WJ, Batch JA. Indexes of insulin resistance and secretion in obese children and adolescents: a validation study. Diabetes Care 2004; 27: 314-319.

18 European Society of Hypertension-European Society of Cardiology Guidelines Committee. 2003 European Society of Hypertension-European Society of Cardiology guidelines for the management of arterial hypertension. J Hypertens 2003; 21: 1011-1053.

19 Bucolo G, David H. Quantitative determination of serum triglycerides by the use of enzymes. Clin Chem 1973; 19: 476-482.

20 Warnick GR, Benderson J, Albers JJ. Dextran sulfate- $\mathrm{Mg}^{2}+$ precipitation procedure for quantitation of high-density-lipoprotein cholesterol. Clin Chem 1982; 28: 1379-1388.

21 Rifai N, Tracy RP, Ridker PM. Clinical efficacy of an automated highsensitivity C-reactive protein assay. Clin Chem 1999; 45: 2136-2141.

22 Levey AS, Stevens LA, Schmid CH, Zhang YL, Castro AF 3rd, Feldman HI et al. A new equation to estimate glomerular filtration rate. Ann Intern Med 2009; 150: 604-612.

23 Erdelmeier I, Gerard-Monnier D, Yadan JC, Chaudiere J. Reactions of $\mathrm{N}$-methyl-2-phenylindole with malondialdehyde and 4-hydroxyalkenals. Mechanistic aspects of the colorimetric assay of lipid peroxidation. Chem Res Toxicol 1998; 11: 1184-1194.

24 Ricart-Jane D, Llobera M, Lopez-Tejero MD. Anticoagulants and other preanalytical factors interfere in plasma nitrate/nitrite quantification by the Griess method. Nitric Oxide 2002; 6: 178-185.
25 Nebot C, Moutet M, Huet P, Xu JZ, Yadan JC, Chaudiere J. Spectrophotometric assay of superoxide dismutase activity based on the activated autoxidation of a tetracyclic catechol. Anal Biochem 1993; 214: 442-451.

26 Flohe L, Gunzler WA. Assays of glutathione peroxidase. Methods Enzymol 1984; 105: 114-121.

27 Zhu H, Zhang L, Amin A, Li Y. Coordinated upregulation of a series of endogenous antioxidants and phase 2 enzymes as a novel strategy for protectig renal tubular cells from oxidative and electrophilic stress. Exp Biol Med (Maywood) 2008; 233: 753-765.

28 Isomaa B, Almgren P, Tuomi T, Forsen B, Lahti K, Nissen M et al. Cardiovascular morbidity and mortality associated with the metabolic syndrome. Diabetes Care 2001; 24: 683-689.

29 McNeill AM, Rosamond WD, Girman CJ, Golden SH, Schmidt MI, East HE et al. The metabolic syndrome and 11-year risk of incident cardiovascular disease in the atherosclerosis risk in communities study. Diabetes Care 2005; 28: 385-390.

30 Van Guilder GP, Hoetzer GL, Greiner JJ, Stauffer BL, Desouza CA. Influence of metabolic syndrome on biomarkers of oxidative stress and inflammation in obese adults. Obesity (Silver Spring) 2006; 14: 2127-2131.

31 Skalicky J, Muzakova V, Kandar R, Meloun M, Rousar T, Palicka V. Evaluation of oxidative stress and inflammation in obese adults with metabolic syndrome. Clin Chem Lab Med 2008; 46: 499-505.

32 Sánchez-Rodríguez M, Martínez-Cruz M, Correa-Muñoz E, Mendoza-Núnez V. Relationship between metabolic syndrome components and oxidative stress in elderly community-dwelling Mexicans. Ann Nutr Metab 2010; 56: 302-307.

33 Fujita K, Nishizawa H, Funahashi T, Shimomura I, Shimabukuro M. Systemic oxidative stress is associated with visceral fat accumulation and the metabolic syndrome. Circ J 2006; 70: 1437-1442.

34 Nicolson G. Metabolic syndrome and mitochondrial function: molecular replacement and antioxidant supplements to prevent membrane peroxidation and restore mitochondrial function. J Cell Biochem 2007; 100: $1352-1369$.

35 Houstis N, Rosen ED, Lander ES. Reactive oxygen species have a causal role in multiple forms of insulin resistance. Nature 2006; 440: 944-948.

36 Arsova-Sarafinovska Z, Eken A, Matevska N, Erdem O, Sayal A, Savaser A et al. Increased oxidative/nitrosative stress and decreased antioxidant enzyme activities in prostate cancer. Clin Biochem 2009; 42: $1228-1235$.

37 Mates JM, Perez-Gomez C, Nunez de Castro I. Antioxidant enzymes and human diseases. Clin Biochem 1999; 32: 595-603.

38 Fortuno A, San Jose G, Moreno MU, Beloqui O, Diez J, Zalba G. Phagocytic NADPH oxidase overactivity underlies oxidative stress in metabolic syndrome. Diabetes 2006; 55: 209-215.

39 Dulak J, Polus M, Guevara I, Hartwich J, Wybranska I, Krzesz R et al. Oxidized low density lipoprotein inhibits inducible nitric oxide synthase, GTP cyclohydrolase I and transforming growth factor beta gene expression in rat macrophages. J Physiol Pharmacol 1999; 50: 429-441.

40 Holmlund A, Hulthe J, Millgard J, Sarabi M, Kahan T, Lind L. Soluble intercellular adhesion molecule-1 is related to endothelial vasodilatory function in healthy individuals. Atherosclerosis 2002; 165: 271-276.

41 Hiramatsu K, Arimori S. Increased superoxide production by mononuclear cells of patients with hypertriglyceridemia and diabetes. Diabetes 1988; 37: 832-837.
(c) (i) () ()
This work is licensed under a Creative Commons Attribution-NonCommercial-NoDerivs 3.0 Un- ported License. To view a copy of this license, visit http:// creativecommons.org/licenses/by-nc-nd/3.0/ 